\title{
Prevalence of HIV in Hospitalized Patients with Venous Thrombosis of the Lower Limbs to the Abidjan Cardiological Institute
}

\author{
Traore Fatoumata \\ Abidjan Heart Institute, Abidjan, Côte d'Ivoire \\ Email: traofa@yahoo.fr
}

How to cite this paper: Fatoumata, T. (2017) Prevalence of HIV in Hospitalized Patients with Venous Thrombosis of the Lower Limbs to the Abidjan Cardiological Institute. World Journal of Cardiovascular Diseases, 7, 435-441.

https://doi.org/10.4236/wjcd.2017.712042

Received: October 30, 2017

Accepted: December 9, 2017

Published: December 12, 2017

Copyright $\odot 2017$ by author and Scientific Research Publishing Inc. This work is licensed under the Creative Commons Attribution International License (CC BY 4.0).

http://creativecommons.org/licenses/by/4.0/

\begin{abstract}
Background: The diagnosis of deep vein thrombosis (DVT) requires an etiological research of HIV infection. The objective was to identify the characteristics of patients with DVT of limbs without other risk factors in our context. Methods: We performed a comparative retrospective study from January 2005 to December 2012. We identified 162 cases of patients hospitalized in Medicine Department of Institute of Cardiology of Abidjan with 124 HIV-negative and 38 HIV positive patients. Results: DVT is more common in HIV positive young patients $(57.8 \pm 15.6$ years vs $39.3 \pm 10.6$ years, $\mathrm{p}=$ 0.0001). The traditional risk factors were found in HIV negative patients. HIV positive patients had no predisposing factor for thrombosis. The ankle-femoral popliteal location ( $29 \%$ vs $73.7 \% \mathrm{p}=0.05$ ) was most frequent in HIV positive patients. There was no significant difference in anticoagulant therapy: UFH ( $60.5 \%$ vs $52.6 \%$; p > 0.05), LMWH (20.2\% vs $7.9 \%$; $p>0.05)$, AVK relay (99.2\% vs $100 \%$; $>0.05$ ) and general measures (elevation MI). $(70.2 \%$ vs $65.8 \% ; \mathrm{p}>0.05)$. None of the patients in both groups had worn stockings in hospitalization. The stockings were prescribed on discharge $(70 \%$ vs 64.7\%; $p$ > 0.05). Conclusion: DVT may be the mode of revelation of HIV infection. The etiological research with HIV infection should be systematic in young patients suffering from DVT in the absence of risk factors of thrombosis.
\end{abstract}

\section{Keywords}

Deep Vein Thrombosis, HIV Infection, Risk Factors

\section{Introduction}

Deep vein thrombosis of lower limbs is a potentially serious and disabling pathology by the complications. It can generate either abruptly via pulmonary 
embolism or secondarily in the long term via post thrombotic syndrome. Every year in France, it affects 50,000 to 100,000 people [1]. The prevention and treatment of deep vein thrombosis must be mandatory in the presence of risk factors [2]. The discovery of a DVT involves a complete assessment of the etiology, including infection with the acquired immunodeficiency virus (HIV). The evidence is that HIV infection is associated with multiple risk factors for thrombosis [3]. Some factors have demonstrated a strong association of HIV infection with DVT: CD4 count $<200 / \mathrm{mm}^{3}$, AIDS disease, protein deficiency C and S. However other risk factors are controversial: treatment by antiproteases, opportunistic infections, the presence of antiphospholipid antibodies including anticardiolopin antibodies and lupus antibodies. The association of HIV infection with deep vein thrombosis seems underestimated in Côte d'Ivoire. This mode of revealing HIV infection by deep vein thrombosis of lower limbs is often ignored in our context.

The objective of this study was to compare the clinical, etiologic, and therapeutic characteristics of patients with deep vein thrombosis of lower limbs by HIV status.

\section{Material and Methods}

\subsection{Population}

From January 2005 to December 2012, 202 files of patients with deep vein thrombosis of the lower limbs were hospitalized in the Department of Medicine of the Abidjan Heart Institute. Their file included a clinical examination, a standard paraclinical assessment including HIV serology.

\subsection{Method}

We carried out a comparative analytical retrospective study over a period of 7 years. These are the files from January 2005 to December 2012

\subsection{Selection Criteria}

The inclusion criteria were the presence of deep vein thrombosis documented by ultrasonography, regardless of location during the course of our study. Concerned the records of patients hospitalized in Medicine at the institute of cardiology of Abidjan. The study excluded 40 incomplete files that did not include venous duplex ultrasound results or HIV serology (19.8\%). A total of $162 \mathrm{pa}$ tients including $124 \mathrm{HIV}$-negative (VN) patients and $38 \mathrm{HIV}$-positive patients (PV) were included.

\subsection{Course of the Study}

We read all the observations to identify the different characteristics of the patients under study. The data was collected on a survey sheet.

In the clinical assessment, the clinical risk factors for thrombosis (obesity, anemia, prolonged bed rest, gynecological obstetric factors and orthopedic sur- 
gery) have been systematically sought. He was also researched the family history of deep vein thrombosis of lower limbs and pulmonary embolism.

A clinical examination including blood pressure (BP), heart rate (HR), weight, height, cardiovascular, pleuropulmonary, abdominopelvic, spleno-ganglionic, urogenital, musculoskeletal and mucocutaneous note.

Complementary examinations included a frontal chest X-ray, an electrocardiogram and an abdominopelvic ultrasound. An abdominopelvic CT scan and the PSA level according to the clinical context (anomaly on the abdominal and / or pelvic ultrasound and abnormal prostate).

The biological assessment noted the results of the blood count, platelet count, sedimentation rate, $\mathrm{C}$ reactive protein, TCK, TP, CD4 count (in case of positive HIV serology).

The search for thrombophilia markers (protein deficiency C and S, antithrombin III), factor 5 Leiden, circulating anticoagulants, antiphospholipids, fibrinogen level, factor Xa) was not achieved because of lack of technical platform.

We have identified the delay in initiating anticoagulant therapy following confirmatory venous duplex and biological assessments of deep vein thrombosis.

The nature and dosage of the anticoagulation, the frequency of the monitoring elements (TCK, platelets and INR) and the relay by antivitamin $\mathrm{K}$ were noted.

\subsection{Statistical Analysis}

Data entry and processing was done using Word, Excel software. The simple description of the sample was made possible by averaging and standard deviation calculations. The Chi-square test was used for the comparison of the percentages and the Student's test for the averages with a risk of error fixed at 5\%. Fisher's exact test was used for small numbers.

\section{Results}

Of the 162 patients, $38 \mathrm{HIV}$-positive cases were diagnosed during the etiological review. The age difference was significant between the groups (57.8 \pm 15.6 years vs. $39.3 \pm 10.6, p=0.0001)$. Suro-poplitofemoral localization was significantly predominant in the HIV-positive group $(29 \%$ vs $73.7 \% \mathrm{p}<0.05)$. On the other hand, the suro-popliteo-femoro-iliac localization was significantly predominant in the HIV-negative group $(61.3 \%$ vs $23.7 \%, \mathrm{p}<0.05)$. There was no significant difference in popliteal location ( $4.8 \%$ vs $2.6 \%, \mathrm{p}>0.05)$ and in the achievement of right lower limbs ( $21.8 \%$ vs $5.3 \%$; p > 0.05), left lower limbs ( $46 \%$ vs $36.8 \%$, p > 0.05 ) or bilateral lower limbs ( $4.8 \%$ vs $2.6 \%, \mathrm{p}>0.05$ ) (Table 1 ).

Traditional risk factors such as obesity, anemia, prolonged bed rest, gynecological obstetric factors and orthopedic surgery have been found in HIV-negative patients. HIV-positive patients had no thrombosis-promoting factors (Table 2). The CD4 count was on average $400 / \mathrm{mm}^{3} \pm 200 / \mathrm{mm}^{3}$.

There were no significant differences in anticoagulant therapy: unfractionated heparin $(60.5 \%$ vs. $52.6 \%, \mathrm{p}>0.05)$, heparin of low molecular weight $(20.2 \%$ vs. 
$7.9 \%, \mathrm{p}>0.05)$, relays by AVK (99.2\% vs $100 \%, \mathrm{p}>0.05)$ and the general measures: elevation of lower limbs (70.2\% vs 65.8\%, p > 0.05) (Table 3).

Table 1. Topography of deep vein thrombosis of lower limbs by HIV serology.

\begin{tabular}{cccc}
\hline Suro popliteo femoral & $36(29 \%)$ & $28(76.7 \%)$ & $<0.05$ \\
Suro popliteo femoro-iliac & $76(61.3 \%)$ & $9(23.7 \%)$ & $<0.05$ \\
Popliteal & $12(9.7 \%)$ & $1(2.6 \%)$ & $>0.0$ \\
\hline
\end{tabular}

Table 2. Demographic data, risk factors, and topography of deep vein thrombosis of lower limbs by HIV serology.

\begin{tabular}{|c|c|c|c|}
\hline & HIV Negatives & HIV Positives & \\
\hline & $\mathrm{n}=124$ & $\mathrm{~N}=38$ & $\mathbf{F}$ \\
\hline Age (years) & $57.8 \pm 15.6$ & $39.3 \pm 10.6$ & 0.0001 \\
\hline $\mathbf{M}$ & $64(51.6 \%)$ & $21(55.3 \%)$ & $>0.05$ \\
\hline F & $60(48.4 \%)$ & $17(44.7 \%)$ & \\
\hline \multicolumn{4}{|l|}{ Risk factors } \\
\hline Anemia & $34(42.7 \%)$ & 0 & $<0.01$ \\
\hline Obesity & $24(19.3 \%)$ & 0 & $<0.01$ \\
\hline Extended bed rest & $19(15.3 \%)$ & 0 & $>0.05$ \\
\hline HTA & $11(8.9 \%)$ & 0 & $>0.05$ \\
\hline Gynecological obstetrics & $2(1.6 \%)$ & 0 & $<0.01$ \\
\hline Taking oestroprogestatives & 5 & 0 & \\
\hline Myoma & 3 & 0 & \\
\hline Caesarean & 2 & 0 & \\
\hline Pregnancy & 1 & 0 & \\
\hline Cancer & $5(4 \%)$ & 0 & $>0.05$ \\
\hline Prostate & 3 & 0 & \\
\hline Within & 1 & 0 & \\
\hline Uterus & 1 & 0 & \\
\hline Tobacco & $3(3.2 \%)$ & 0 & $>0.05$ \\
\hline Orthopedic surgery & $11(8.9 \%)$ & 0 & $>0.05$ \\
\hline Other & & & \\
\hline
\end{tabular}

Table 3. Inpatient treatment received by patients by HIV serology.

\begin{tabular}{cccc}
\hline Inpatient Treatment & HIV Negatives & HIV Positives & \multirow{2}{*}{$\mathbf{p}$} \\
\cline { 2 - 3 } & $\mathbf{n}=\mathbf{1 2 4}$ & $\mathbf{n}=\mathbf{3 8}$ & \\
\hline Relay by AVK & 84 & 20 & NS \\
Heparin Unfractionated & 123 & 38 & NS \\
Heparin of Low Molecular Weight & 25 & 3 & NS \\
Stockings & 0 & 0 & \\
Heparin Association-AVK & 19 & 7 & NS \\
Elevation of lower limbs & 75 & 31 & NS \\
\hline
\end{tabular}

AVK: Antivitamin K; MI: Inferior Members. 
TCK was daily in patients who received standard heparin and the platelet count was biweekly. The administration of unfractionated heparin was stopped on average after 4 days when the INR was between 2 and 3 . The INR control was performed every 48 hours. Hemorrhagic complications and heparin-induced thrombocytopenia were not observed in both groups. None of the patients in both groups had compression stockings in hospital. The lows were prescribed at discharge (70\% vs. $64.7 \%, \mathrm{p}>0.05)$.

\section{Discussion}

In this study of patients with deep vein thrombosis of lower limbs, the 38 positive HIV cases were discovered incidentally. These patients were in good general condition with no particular history of CD4 levels within normal limits. They had no opportunistic affections or antiretroviral treatment. HIV infection is known to be a provider of deep vein thrombosis [4] [5]. It affects mainly young people as in our study [4]. The age of HIV positive patients reported in the literature is around 40 years [6] [7]. In patients younger than 50 years, the risk of deep vein thrombosis is higher in HIV-positive patients than in HIV-negative patients [5] [8].

In general, the occurrence of deep vein thrombosis is multifactorial in the general population [9] [10]. In young subjects without other factors promoting thrombosis, HIV infection should be considered [11] as in the case of our study. Indeed, the cardiovascular attacks of HIV infection are multiple. They reach the pericardium, endocardium and myocardium [8] [9] [10]. The frequency of deep vein thrombosis during HIV infection appears to be related to the depth of immunosuppression with low CD4 count: $<200$ [12]. The patients in our study had a CD4 count between 200 and 400. The risk is higher with a CD4 count close to 200. Authors have demonstrated a strong association between deep vein thrombosis and stage AIDS disease with opportunistic conditions [5]. Protein deficiency $\mathrm{C}$ and $\mathrm{S}$ are also an additional risk factor for thrombosis [13]. The relationship between protein $\mathrm{C}$ deficiency and deep vein thrombosis is not as clear as for protein $\mathrm{S}$ deficiency. On the other hand, there is a high prevalence of protein $\mathrm{C}$ deficiency in HIV-positive patients without other risk factors for thrombosis. [13]. In any case, the syndrome of inflammation (accelerated sedimentation rate and elevated $\mathrm{C}$ reactive protein) is favorable for an alteration of the vascular wall thus constituting the bed of this thrombosis in the seropositive. Thus, in HIV positive patients, vascular tropism of HIV and acquired thrombophilia would be conducive to the onset of deep vein thrombosis of lower limbs [14].

Antiretroviral therapy, especially anti-proteases, is associated with the occurrence of thrombotic events [15]. Patients in our study were not on antiretroviral therapy to explain this thrombosis.

The anticoagulation strategy is identical in both groups of patients. Unfractionated heparin was the most used anticoagulant in both groups. Heparin of 
low molecular weight has shown its effectiveness.

\section{The Limits of the Study}

For the etiological research, we could not make the assessment of the thrombophilia because of the insufficient technical platform.

Like any retrospective study, we only use the complete files comprising venous Doppler lower limbs and serology HIV.

\section{Conclusion}

Deep vein thrombosis was the circumstance of discovery of HIV infection in patients in our study. These patients were young without any well-identified thrombosis-promoting factor in our work setting. The etiologic assessment for HIV infection should be systematic in young subjects with supra-popliteo femoral thrombosis in the absence of other factors promoting thrombosis, as well as the search for protein deficiency $\mathrm{C}$ and $\mathrm{S}$ and inflammatory status (sedimentation rate and $\mathrm{C}$ reactive protein).

\section{References}

[1] Goldhaber, S.Z. (2012) Bounameux Pulmonary Embolism and Deep Vein Thrombosid. The Lancet, 379, 1835-1846. https://doi.org/10.1016/S0140-6736(11)61904-1

[2] Goldhaber, S.Z. (2010) Risk Factors for Venous Thromboembolism. Journal of the American College of Cardiology, 56, 1-7. https://doi.org/10.1016/j.jacc.2010.01.057

[3] Kiser, K.L. and Badowski, M.E. (2010) Risk Factors for Venous Thromboembolism in Patients with Human Immunodeficiency Virus Infection. Pharmacotherapy, 30, 1292-1302. https://doi.org/10.1592/phco.30.12.1292

[4] Wilkerson, W.R. and Sane, D.C. (2002) Aging and Thrombosis. Seminars in Thrombosis and Hemostasis, 28, 555-567. https://doi.org/10.1055/s-2002-36700

[5] Jacobson, M.C., Debuze, B.J. and Aboulafia, D.M. (2004) Thrombotic Complications in HIV Infected Patients Highly Active Antiretroviral Therapy: A Case Series. Clinical Infectious Diseases, 39, 1214-1222. https://doi.org/10.1086/424664

[6] Saif, M.W. and Bona, R.B. (2002) Greenberg and Thrombosis Retrospective Study of 131HIV-Infected Patients. AIDS Patient Care STDS, 15, 311-320. https://doi.org/10.1089/108729101750279687

[7] Copur, A.S., Smith, P.R., Gomez, V., et al. (2002) HIV Infection Is a Risk Factor for Venous Thrombolism. AIDS Patient Care STDS, 16, 205-209. https://doi.org/10.1089/10872910252972258

[8] Barbaro, G. (2001) Cardiovascular Manifestations of HIV Infection. Journal of the Royal Society of Medicine, 94, 384-389. https://doi.org/10.1177/014107680109400804

[9] Amati, G.D., Gioia, P. and Galio, P. (2001) Pathological Finding of HIV Associated Cardiovascular Disease. Annals of the New York Academy of Sciences, 946, 23-45. https://doi.org/10.1111/j.1749-6632.2001.tb03901.x

[10] Hajjar, L.A., Calderaro, D., Yu, P.C., et al. (2005) Cardiovascular Manifestations in Infected Patients with the Human Immunodeficiency Virus. Arquivas Brasileiros of Cardiology, 85, 363-377.

[11] Bibas, M., Biava, G. and Antinori, A. (2011) HIV-Associated Venous Thromboem- 
bolism. Mediterranean Journal of Hematology and Infectious Diseases, 3, 2035-3006. https://doi.org/10.4084/mjhid.2011.030

[12] Deeks, S.G. and Phillips, A.N. (2009) HIV Infection, Antiretroviral Treatment, Age and Non-AIDS related Morbidity. BMJ, 26, 288-292.

[13] Majluf-Cruz, A., Silva-Estrada, M., Sanchez-Barboza, R., et al. (2004) Venous Thrombosis among Patients with AIDS. Clinical and Applied Thrombosis/Hemostasis, 10, 19-25. https://doi.org/10.1177/107602960401000104

[14] Thompson 3rd, G.R., Lawence, V.A. and Crawford, G.E. (2007) HIV Infection Increases the Risk of Heparin Induced Thrombocytopenia. Clinical Infectious Diseases, 45, 1393-1396. https://doi.org/10.1086/522761

[15] Hobrook, A.M., Pereira, J.A., Laboris, R., et al. (2005) Systematic Overview of Warfarin and Its Drug and Food Interactions. Archives of Internal Medicine, 165, 1095-106. https://doi.org/10.1001/archinte.165.10.1095 